\title{
Reinvenção do Ensino da Língua Portuguesa e Literatura na Escola: Propostas de Alunos Estagiários em Letras
}

\author{
Reinvención de la Enseñanza de Lengua Portuguesa y Literatura en la \\ Escuela: Propostas de Alumnos Practicantes en Letras
}

\begin{abstract}
Dra. Ida Maria Morales Marins'; Hohanne da Silva Vilela²; Renan Cardozo da Silva ${ }^{3}$; Rocheli R. Predebon Silveira ${ }^{4}$

1idamariamarins@gmail.com, Universidade Federal do Pampa; ${ }^{2}$ hannavilelaarmas@ hotmail.com, Universidade Federal do Pampa; ${ }^{3}$ renancardozoo@gmail.com, Universidade Federal do Pampa; ${ }^{4}$ rocheli.silveira@ hotmail.com, Universidade Federal do Pampa.
\end{abstract}

\begin{abstract}
Resumo
O trabalho, aqui apresentado, é resultado das práticas de letramento, em especial, de letramento literário levadas a cabo no período de estágio de discentes do Curso de Letras, via projeto de extensão Experiências de leitura/escrita: a formação de leitores/escritores. $\mathrm{O}$ objetivo deste texto é o de relatar duas propostas de ensino com o texto literário, trazendo uma metodologia específica que visa apresentar, aos futuros profissionais das Letras, uma possibilidade fértil de trabalhar com a língua e a literatura na escola. Também, traz uma breve abordagem teórica sobre letramento, para situar o leitor sobre o significado de tal termo. Como resultado das práticas desenvolvidas ao longo do estágio, foi possível perceber a diversidade e riqueza de ações que podem perpassar a sala de aula de língua e literatura, transformando esse espaço em espaço de prazer, de aprendizagens significativas que mobilizam a criatividade, a criticidade e o desenvolvimento do prazer pela leitura e escrita.
\end{abstract}

Palavras-chave: letramento; ensino de língua e literatura; estágio de docência.

\section{Resumen}

El trabajo, aquí presentado, es resultado de las prácticas de lectoescritura, principalmente, de lectoescritura literario llevadas a cabo en el periodo de la pasantía de discentes del Curso de Letras, mediante el proyecto de extensión de lectura/escrita: la formación de lectores/escritores. El objetivo de este texto es el de relatar dos propuestas de enseñanza con el texto literario, trayendo una metodología especifica que propone presentar, a los futuros profesionales de Letras, una posibilidad fértil de trabajar con la lengua y la literatura en la escuela. Además, trae un breve abordaje teórico sobre lectoescritura, para situar al lector sobre el significado de dicha terminología. Como resultado de las prácticas desarrolladas a lo largo de la pasantía fue posible percibir la diversidad y riqueza de las acciones que pueden rebasar la clase de lengua y literatura, transformando ese espacio en espacio de placer, de aprendizajes significativos que movilizan la creatividad, la criticidad y el desarrollo del placer por la literatura y escrita.

Palabras-clave: lectoescritura; enseñanza de lengua y literatura; pasantía de docencia. 


\section{Introdução}

O projeto de extensão Experiências de leituralescrita: a formação de leitores/escritores ${ }^{1}$ foi proposto, inicialmente, pela área de Literatura do Curso de Letras da Universidade Federal do Pampa/campus Jaguarão/RS. No ano seguinte, 2010, a área de Língua Portuguesa integra-se ao projeto em um trabalho de parceria entre as duas áreas. Seu principal objetivo é o de incentivar a formação de leitores a partir da prática de leitura de múltiplos gêneros discursivos; como também desenvolver o desejo pela produção escrita como manifestação individual e coletiva na promoção da cidadania.

As ações previstas no projeto incluem o trabalho com alunos do ensino fundamental e médio realizadas pelos discentes de Letras, em situação de prática de estágio ou não. Também, alia-se a preocupação com a formação continuada dos profissionais do ensino básico, ofertando oficinas que tratam da temática central do projeto, buscando desenvolver a consciência da relevância no investimento de propostas de ensino com a leitura e a escrita mobilizadoras de prazer. Tendo em vista a importância de atuar na formação do gosto pela leitura e escrita, o projeto possibilita o contato dos estudantes com textos artísticos de diversos gêneros, fomentando o prazer da leitura/escrita, e o desenvolvimento da capacidade crítica do leitor frente a diferentes práticas discursivas. Para isso, há uma preparação dos discentes de Letras que, ao atuarem como mediadores entre o texto ficcional e os estudantes, assumem a experiência de docência via ações de extensão em suas práticas de estágio.

A proposta metodológica orientadora do planejamento e das práticas realizadas com os alunos nas escolas foi a do Letramento Literário (COSSON, 2011). O autor propõe, em sua metodologia, uma reformulação e o fortalecimento da educação literária na escola de ensino básico com o argumento da necessidade de se formar comunidades de leitores, iniciadas na sala de aula e estendidas para além dessa, tornando os alunos capazes de interagir de modos diferentes - ver e viver - com o mundo.

Este artigo propõe-se a tratar do desenvolvimento das práticas de estágio de docência de quatro discentes de Letras, via o projeto de extensão Experiências de leitura/escrita: a formação de leitores/escritores, trazendo, na voz dos próprios alunos, relatos de experiências, reflexões acerca do significado das práticas na construção de comunidades de

\footnotetext{
1 Esse projeto foi proposto pela professora de literatura Cátia Goulart, em 2009, e tinha como título: Experiências de leitura: a formação de leitores. Em 2010, a professora de língua portuguesa Ida Maria Marins passa a integrá-lo, dando origem ao nome atual. Maiores informações do projeto, acessar: experienciasdeleitura.blogspot.com.br.
} 
leitores/escritores, como também uma avaliação sobre a metodologia de trabalho posta em execução.

Para tanto, dividimos o artigo em partes. Na primeira, tratamos do significado de letramento e de letramento literário, trazendo à tona as teorias desenvolvidas por Soares (2011, 2012) e Cosson (2011), respectivamente. Na segunda parte, apresentamos a metodologia de trabalho proposta por Cosson; seus fundamentos e orientações para colocá-la em prática de modo a garantir um trabalho organizado e bem planejado com o texto literário na educação básica. Na terceira parte, temos a apresentação, pelos discentes de Letras, das práticas realizadas no campo de estágio com os gêneros literários: contos de fadas e suas possíveis releituras, e lendas e contos da cidade de Jaguarão. Além da apresentação, encontramos uma avaliação das implicações desse trabalho na formação do gosto pela leitura/escrita e na vida dos alunos envolvidos, como também a viabilidade de aplicação de uma metodologia para trabalhar o texto literário na escola. Na parte final, trazemos nossas considerações acerca do desenvolvido, apontando dificuldades enfrentadas na execução do trabalho, compreensões, incompreensões dos parceiros nesse processo - as escolas; e sugestões possíveis para a continuidade ao projeto.

Desde já, gostaria de agradecer imensamente a coragem, o desprendimento e comprometimento dos discentes que desejaram apostar numa prática de estágio diferenciada daquilo que comumente acontece. Digo diferenciada porque se trata de uma proposta que ousa ressignificar o trabalho com o texto literário, ainda um tanto prescritivo nas práticas escolares. Também diferenciada, porque prima por ouvir as vozes dos alunos, seus sentimentos, suas leituras do mundo que os cerca, favorecendo leituras mais críticas, a aquisição de conhecimentos e o despertar da consciência de que é possível participar de práticas de letramento até então desconhecidas por eles - como o caso da elaboração de um livro de histórias.

\section{Letramento e letramento literário}

No Brasil, o termo letramento aparece a partir da segunda metade dos anos 80. Há a hipótese de que tenha surgido com a autora Mary Kato (1986) em seu livro: No mundo da escrita: uma perspectiva psicolinguística e, logo após, foi trazido nos estudos e pesquisas de Tfouni (1988), Kleiman (1995) e Soares (1998). Na época, esse termo surge como uma forma de problematização à concepção de alfabetização, vista como um processo de codificação e decodificação do signo linguístico. Nas palavras de Soares (2011, p. 15) “etimologicamente o 
termo alfabetização não ultrapassa o significado de levar à aquisição do alfabeto, ou seja, ensinar o código da língua escrita, ensinar as habilidades de ler e escrever". O sujeito torna-se alfabetizado por que adquire as habilidades de leitura e escrita, sendo a escola o espaço legitimado de poder que lhe confere essa capacidade.

Contudo, Soares (2011) enfatiza que o conceito de alfabetização é bastante complexo, pois abrange diferentes pontos de vista. Tanto pode ser visto numa perspectiva mecânica da escrita, ou seja, aprender a representar fonemas (sons) em grafemas (letras) e, assim, viceversa; como também, pelo ponto de vista do processo de compreensão e expressão de significados advindos da capacidade de ler e escrever. Para além dessas duas formas de pensar a alfabetização, a mesma autora apresenta um terceiro ponto de vista que tem origem no social e não somente no individual como as duas formas anteriores. São as diferentes formas dos grupos e sociedades encararem o processo de alfabetização: para um agricultor a alfabetização atende a necessidades específicas, sociais diferentes das de um trabalhador urbano, por exemplo.

A palavra letramento surge com o objetivo de responder a uma nova realidade social para a qual o ato simples de saber ler e escrever não são suficientes para dar conta dos avanços tecnológicos e das novas exigências da sociedade. É preciso também “ saber fazer uso do ler e do escrever, saber responder às exigências de leitura e de escrita que a sociedade faz continuamente" (SOARES, 2012, p. 20). Nesse sentido, letramento passa a ser entendido como um estado ou condição que um indivíduo ou grupo social adquire como consequência da sua capacidade de fazer uso da leitura e da escrita com objetivos sociais.

$\mathrm{O}$ ato de saber fazer uso da leitura e da escrita nas mais diferentes práticas sociais significa dar ao sujeito a possibilidade e as condições para questionar, concordar, discordar, agir mediante o uso da palavra. Para que isso se efetive é fundamental que a escola cumpra seu papel no desenvolvimento do letramento, embora se saiba que isso pode acontecer fora do espaço escolar. Como agência principal desse processo, cabe à escola repensar seus modos de conceber o ensino, ainda um tanto preso às prescrições e propor um currículo que oportunize o engajamento discursivo dos alunos nas práticas sociais, de modo que possam aprender novos conhecimentos, ressignificar outros e perceberem-se agentes na construção da sua aprendizagem.

Mas qual o papel da literatura, na escola, nesse processo de desenvolvimento do letramento? Para Cosson (2011, p. 23) “... o letramento literário é uma prática social e, como tal, responsabilidade da escola". A isso, acrescentamos que a escola tem o compromisso de promover o letramento literário de forma significativa aos alunos. Para tanto, é necessário que 
a universidade implemente nos currículos dos cursos de licenciatura em Letras, disciplinas, projetos voltados ao trabalho com o ensino da literatura na educação básica. Destarte, os futuros professores estarão mais capacitados para atuarem como agentes do letramento literário.

Para tentar elucidar o termo letramento literário, trazemos duas estrofes de um poema de uma estudante norte-americana - Kate M. Chong quando busca definir letramento a partir da sua história de aprendizagem. O poema foi retirado do livro de Soares ( 2011, p. 41), Letramento: um tema em três gêneros, e nos diz:

\author{
Letramento é diversão \\ é leitura à luz de vela \\ ou lá fora, à luz do sol. \\ É viajar para países desconhecidos, \\ sem deixar sua cama, \\ é rir e chorar \\ com personagens, heróis e grandes amigos.
}

Percebemos o papel da literatura no desvelamento da palavra que vai muito além do seu mero significado. O prazer que ela mobiliza - oportunizando a cada um sonhar, emocionar-se, viajar por mundos mais diversos da ficção - dá ao sujeito a possibilidade de viver uma nova experiência. Para Cosson (2011, p. 17)

\footnotetext{
Na leitura e escritura do texto literário encontramos o senso de nós mesmos e da comunidade a que pertencemos. A literatura nos diz o que somos e nos incentiva a desejar e expressar o mundo por nós mesmos. E isso se dá porque a literatura é uma experiência a ser realizada. É mais um conhecimento a ser reelaborado, ela é a incorporação do outro em mim sem renúncia da minha própria identidade. No exercício da literatura, podemos ser outros, podemos viver como os outros, podemos romper os limites do tempo e do espaço de nossa experiência e, ainda assim, sermos nós mesmos.
}

Pensando a literatura como modo de encontro com o outro e consigo mesmo, de reencontros, afirmações, ressignificações, aprendizado, (trans)formação subjetiva, tudo através da magia e do deleite que a palavra nos proporciona e, compreendendo que a escola é, segundo Kleiman (2007), a principal agência de letramento; investimos em projetos os quais tiveram por objetivo principal incentivar a formação de leitores e escritores a partir da prática da leitura de textos literários que mobilizassem o prazer, o conhecimento do outro e de si de forma a favorecer o processo de humanização tão importante na formação das gerações. 
O relato do trabalho realizado com esses projetos são trazidos, aqui, com o intuito de colaborar com potenciais leitores que estejam interessados em pensar práticas de ensino com o texto literário na escola e fomentar o incentivo e desenvolvimento do letramento literário.

Antes de trazer os relatos, apresentamos a metodologia utilizada para colocar em prática as ações planejadas.

\section{A proposta metodológica}

Conforme já explicitamos, a metodologia de trabalho seguiu as orientações da proposta de letramento literário de Cosson (2011). Segundo o autor, uma proposta metodológica para o letramento literário, na educação básica, fortalecerá a construção de uma comunidade de leitores e incentivará que o trabalho com a leitura se dê de forma contínua, "partindo do conhecido para o desconhecido, do simples para o complexo, do semelhante para o diferente..." (COSSON, 2011, p. 47-48). A partir desse entendimento, propõe uma sistematização das atividades em sala de aula de literatura, as quais são definidas em: sequência básica e sequência expandida. Para o nosso trabalho, escolhemos a sequência básica por entender que as etapas do seu desenvolvimento estavam mais de acordo com as nossas possibilidades, principalmente, relativas ao tempo que teríamos com os alunos.

A sequência básica pressupõe as seguintes etapas: motivação, introdução, leitura e interpretação. A seguir, explicaremos o objetivo de cada uma delas. Vale destacar que esses passos são entendidos pelo autor como exemplares e não modelares. Isso significa que servem de parâmetros para que os professores possam se utilizar, fazendo adaptações, criando a partir dos seus objetivos e realidades.

A motivação tem por propósito despertar o interesse dos alunos na leitura que será apresentada. Ela deve instigar a curiosidade através de atividades, sejam de escrita ou oralidade, que possibilitem às crianças, aos jovens ou adultos trazerem suas experiências de mundo, seus conhecimentos relativos à temática do texto a ser trabalhado. Segundo Cosson, “[...] as mais bem-sucedidas práticas de motivação são aquelas que estabelecem laços estreitos com o texto que se vai ler a seguir" (p. 55).

A introdução é um procedimento relativamente simples e de curta duração. Cabe ao professor apresentar o autor e a obra que vai ser trabalhada. São informações, não extensas, de ordem textual e paratextual que contribuam para despertar o "gostinho" de querer saber mais sobre o autor e, principalmente, sobre a obra. Importante, também, nesse momento da 
introdução, é deixar os alunos manusearem o livro, senti-lo, apalpá-lo, cheirá-lo, folheá-lo. Isso, por certo, é mais um passo rumo à conquista para a leitura que virá a seguir.

A leitura é o momento de adentrar o texto, sabendo, professor e alunos, que existe um objetivo a ser alcançado. Toda leitura escolar deve ser acompanhada pelo professor, que assumirá a posição de mediador entre autor, texto e leitor. Nesse processo, cabe ao professor promover momentos ou intervalos, como menciona Cosson, que possam oportunizar o diálogo, a emergência de compreensões, a verificação das dificuldades encontradas, o envolvimento participativo dos alunos na leitura proposta.

A interpretação pode ser vista como o momento ápice do letramento literário. É quando os alunos passam a representar os sentidos produzidos nas suas leituras. Cosson entende que a interpretação se dá em dois momentos: um interior e outro exterior. O primeiro é quando o leitor faz suas inferências pessoais com a influência das etapas anteriores de motivação, introdução e da leitura da obra, como também sob a influência das suas experiências de mundo, da sua história de vida, sendo, portanto, sempre um ato social, apesar da sua individualidade na interpretação. O momento exterior significa a materialização da interpretação, que pode ser realizada através de várias atividades e cujo objetivo é o de fazer com que todos compartilhem suas interpretações, suas produções de sentido, estendendo-as à comunidade, seja escolar, familiar, ou a outros espaços sociais. Para Cosson, no momento da interpretação "o importante é que o aluno tenha a oportunidade de fazer uma reflexão sobre a obra lida e externalizar essa reflexão de uma forma explícita...” (p. 68).

Após apresentarmos uma síntese da metodologia que orientou os planejamentos e as ações didático-pedagógicas realizadas no período de estágio dos discentes de Letras, trazemos os relatos das práticas, na voz dos próprios alunos-estagiários, co-autores deste texto.

\subsection{Contos de fadas e suas possíveis releituras}

O trabalho desenvolvido no componente curricular Estágio III, vinculado ao Projeto de extensão Experiências de leitura/escrita: a formação de leitores/escritores, foi realizado na escola E. M. E. F. General Antônio de Sampaio e consistiu no desenvolvimento de práticas com vistas à formação de leitores e escritores partindo do gênero literário contos de fadas. Para tanto, trabalhamos com os contos: Chapeuzinho Vermelho, Pinóquio, Branca de Neve e Barba Azul. Nosso propósito foi o de levar atividades aos alunos para que eles ampliassem seus sensos de criatividade e desenvolvessem a capacidade de leitura e escrita. Além disso, 
buscamos desenvolver a criticidade desses leitores, partindo de questões relacionadas aos gêneros masculino/feminino.

A partir das orientações da sequência didática básica que inclui: motivação, introdução, leitura e interpretação, trazemos um relato das práticas realizadas no decorrer do projeto. Por questão de espaço neste artigo, elegemos apresentar os contos Chapeuzinho Vermelho e Pinóquio para, posteriormente, refletirmos acerca do trabalho desenvolvido.

A primeira parte trabalhada com os alunos foi a da motivação. Com base nessa orientação, introduzimos o conto da Chapeuzinho Vermelho fazendo alguns questionamentos: se conheciam a personagem, o que sabiam sobre ela, quais histórias tinham ouvido falar envolvendo a personagem, entre outros. Esses questionamentos serviram para ativar os conhecimentos prévios dos alunos sobre o conto, relatando as versões do texto que cada um conhecia e até as versões fílmicas, que posteriormente trabalhamos. Já no conto do Pinóquio, trabalhamos a percepção dos alunos em relação à mentira, perguntando sobre o modo como eles agiam quando praticavam algo julgado como "errado"; se mentiam ou contavam a verdade. Quanto a isso, a maioria dos alunos relatou que mentiam ao fazer algo errado para não sofrer as consequências. Depois, perguntamos aos alunos se conheciam algum conto que tratasse da mentira para, assim, introduzirmos o texto do Pinóquio.

Como introdução, levamos aos alunos uma contextualização sócio-histórica acerca de cada conto. Sobre a Chapeuzinho Vermelho foi entregue um resumo contendo informações sobre a origem da história, com isso, os alunos puderam compreender de onde e como surgiu o conto, e como esse conto era importante mundialmente. O texto do Pinóquio foi introduzido através de uma conversa sobre o contexto de produção do conto: a época em que ele foi escrito e quais relações sociais se estabeleciam naquele momento. Com isso, os alunos puderam trazer suas experiências relacionadas a algum aspecto do conto.

Para trabalhar a leitura, levamos, além das versões clássicas dos contos, outras leituras através de músicas, filmes e imagens. No conto da Chapeuzinho Vermelho, contrapomos as versões escritas dos autores Charles Perroult e a de Luis Felipe Silva e Élida Borges: Uma chapeuzinho bem brasileira, além da versão cinematográfica Deu a louca na chapeuzinho Vermelho e da música Chapeuzinho, do grupo Tribo da Periferia. Ao trabalhar com as diferentes versões do conto, pudemos contrapor as relações de gênero feminino/masculino, existentes em cada época e, assim, refletir sobre como essa relação mudou com o decorrer dos anos.

No conto Pinóquio, contrapomos a versão clássica com a música Pinóquio e Emília de Flávio Paiva. Assim, fizemos também uma comparação entre os personagens Pinóquio e 
Emília, lembrando os alunos para os diferentes contextos utilizados na produção, circulação e recepção desses textos.

Na quarta e última etapa da sequência didática - a interpretação, propomos, além de uma retomada dos textos escritos e imagéticos, a produção de outros textos e a criação de imagens. No conto da Chapeuzinho Vermelho, contrapomos as diferentes versões e questionamos os alunos em relação ao que pensavam sobre os vários discursos presentes nos textos, focando, principalmente, na relação entre os gêneros feminino/masculino. Nesse sentido, mostramos a importância de tais discursos na representação social de tais gêneros e qual a sua influência na sociedade atual. Como registro material da interpretação, os alunos produziram a imagem de um dos personagens do conto com o objetivo de transpor para o desenho a sua representação física e psicológica do personagem escolhido.

Com o conto Pinóquio, estabelecemos um paralelo entre os personagens Pinóquio e Emília. Para tanto, partimos de questionamentos acerca do significado dos gêneros masculino e feminino dos personagens, discutindo como a escolha desses gêneros era representada em cada época do texto. Depois, os alunos criaram um conto em que apareciam os dois personagens em interlocução.

\subsubsection{Algumas reflexões}

A proposta decorreu de um longo trabalho de busca de materiais que envolvessem a prática que pretendíamos. Fomos em busca de atividades pedagógicas que contemplassem o público a que se destinava o ensino, porém, tivemos dificuldades de encontrá-las. Com isso, partimos para a elaboração, nós mesmas, da maior parte das atividades as quais envolvessem os contos clássicos infantis, mais conhecidos como contos de fadas para crianças de 11, 12 e 13 anos de idade. Preparar as atividades foi desafiador, mas ao mesmo tempo, motivador. Após planejamento e elaboração das primeiras atividades, as colocamos em execução sem termos a noção de como seriam recebidas. Para a nossa alegria, a maioria dos alunos gostou do que propomos, o que nos incentivou a dar seguimento ao trabalho dentro da linha pensada: trabalhar com diferentes gêneros textuais. Buscamos músicas, imagens, filmes e textos escritos. Essa diversidade de gêneros enriqueceu o trabalho e motivou a participação das crianças.

O ensino de língua materna não é fácil, principalmente no que tange o trabalho com a leitura, o texto, a produção textual e aspectos linguísticos, que é a proposta dos Parâmetros Curriculares Nacionais (1996). Contemplar esses eixos tornou, por vezes, difícil a nossa 
prática, pois percebemos que o ensino requer muito mais que conseguir vencer conteúdo. $\mathrm{O}$ ensino requer motivação, ou seja, se estamos motivados não importa o quão ruim tenha sido nossa aula em um determinado momento, pois buscaremos algo reconfortante e que responda melhor aos nossos objetivos e também aos interesses dos alunos para desenvolver a sua aprendizagem. Carvalho, Pereira e Ferreira citam Bzuneck (2001), que afirma: “[...] alunos desmotivados estudam muito pouco ou nada e, consequentemente, aprendem muito pouco" (p. 13). Isso quer dizer que, ao motivarmos os alunos, podemos melhorar o desempenho deles, como ocorreu em algumas atividades.

$\mathrm{O}$ que vimos foi que os alunos adoravam trazer suas experiências quando abríamos espaços para o diálogo nos momentos de contrapor os conteúdos com o mundo real, quando contrapúnhamos os contos infantis com a História. Nesse sentido, cabe o que nos cita Bahktin (1999), ao tratar dos enunciados, "a língua penetra na vida através dos enunciados concretos que a realizam, e é também através dos enunciados concretos que a vida penetra na língua" (p. 282). Precisamos olhar para as aulas de língua materna e literatura, refletindo sobre o que fazemos ali, como sujeitos que podem fazer a diferença na vida de outras pessoas, alertandolhes sobre alguns manejos da língua e suas linguagens. Desse modo, saberemos o que nos motiva e o que pode dar certo.

Por fim, podemos dizer que a tarefa do professor não é fácil ou simples e, por isso, há a necessidade de investimento em práticas que possam contribuir para a melhoria do ensino, bem como para o aperfeiçoamento e reconhecimento do profissional da educação. Mas para isso, necessitamos de um trabalho integrado, não somente da escola ou das universidades, mas também de outras esferas públicas e privadas da sociedade.

As práticas desenvolvidas no estágio de docência, via projeto de extensão, oportunizaram, junto à escola, a conscientização dos alunos sobre a importância da leitura em suas vidas pessoais, bem como profissionais e acadêmicas futuras. Nesse sentido, a contribuição deixada no desenvolvimento do estágio parece ter auxiliado a escola em projetos futuros, pois percebemos que os alunos adquiriram outro nível de leitura, tornando-se leitores e escritores mais conscientes de suas capacidades e requerendo da escola a continuidade do projeto, o que para nós significou sobrema

\subsection{Lendas e contos da cidade de Jaguarão}

A Escola Municipal de Ensino Fundamental Fernando Corrêa Ribas, localizada no município de Jaguarão, abarca alunos da periferia da cidade. É uma escola que busca, através 
de projetos ofertados pela Universidade Federal do Pampa, a formação continuada de seus professores a fim de oportunizar uma educação de qualidade, levando em conta o contexto social dos alunos e da sociedade. Sendo assim, buscamos, através das nossas práticas de estágio supervisionado em língua portuguesa e literatura, resgatar aspectos da cultura jaguarense por meio de contos, lendas e histórias orais do município, visto que antigamente essas histórias eram presentes no cotidiano das pessoas, mas com os efeitos da globalização esses artefatos culturais acabaram ficando meio esquecidos.

O texto, a seguir, traz um relato do planejamento das aulas: passos realizados para o desenvolvimento das atividades, reflexões em diálogo com a teoria e a conclusão, trazendo nossas percepções acerca do trabalho desenvolvido. Como aporte teórico, utilizamos Cosson (2011), que apresenta uma metodologia de trabalho com o texto literário; Leite (2006), que questiona o uso da literatura como pretexto para o ensino de gramática; Geraldi (2006), tratando da produção de textos em sala de aula e Santos (2010), que apresenta o conceito de cultura adotado neste trabalho.

Nosso planejamento visou o incentivo da leitura e da escrita por meio do letramento literário, de modo a fomentar a construção de sentidos (Cosson, 2011), partindo da premissa de que estamos em uma região de fronteira Jaguarão - BR/Rio Branco - UY e que, muitas vezes, a nossa cultura se mescla com a uruguaia através de artefatos como contos, músicas, danças, entre muitos outros. Ancorados em Santos, adotamos a definição de cultura como uma forma de interação que vê a diversidade como ponto culminante das relações sociais. Segundo o autor, "quando falamos em cultura estamos nos referindo mais especificamente ao conhecimento, às ideias e crenças, assim como às maneiras como eles existem na vida social" (SANTOS, 2010, p. 21).

Seguindo as etapas propostas por Cosson (2011), primeiramente trabalhamos com a motivação, realizando discussões sobre o que os estudantes achavam do nosso município e se sabiam como ele fora criado, assim, voltamos à criação de Jaguarão e propomos que os alunos buscassem histórias que contassem a sua construção. Dando continuidade às etapas, na introdução, seguimos falando da construção da cidade, utilizando contos e lendas, como a do "Jaguarú" do escritor jaguarense Hélio Ramirez, aproximando os alunos da nossa proposta visto que, ao decorrer da leitura, perguntávamos, por exemplo, em que lugar a lenda se passava, que mudanças ocorreram na cidade desde aquela época e quais modificações o rio sofreu; com isso, mostramos para os estudantes que os elementos que compunham a lenda eram de fato reais, proporcionando uma visão da história da cidade com elementos bem detalhados e fieis à realidade. Na terceira etapa da sequência didática, nomeada de leitura, 
trabalhamos com os contos "As grandes Onças Brabas" e "Primeiro de Janeiro" do escritor jaguarense Aldyr Gracia Schlee a fim de discutir a cultura jaguarense e as influências sofridas pela cidade por conta da fronteira. Como essa etapa pressupõe intervalos, realizamos, em meio às leituras, atividades de produção textual, passeios, mostras fílmicas e reescritas de textos, tendo por base os contos que estávamos trabalhando. Para concluir a última etapa, $a$ interpretação, compilamos todas as produções textuais (contos e lendas) e, juntamente com os alunos, organizamos um livro.

Como o livro foi de autoria dos alunos, propusemos que eles escolhessem um título, que se deu através de votação. Sentamos todos em uma roda para pensar possíveis nomes e, à medida que iam sugerindo, perguntávamos o que os demais achavam, mas sempre havia alguém que não gostava, até que uma aluna propôs o titulo "Histórias Obscuras e Lendas Sem Fim" e todos acharam o máximo, pois resumia todo o conteúdo do livro. Nesse livro, reunimos diversas histórias, fictícias e reais sobre o município, as quais foram produzidas e reescritas durante as aulas. Assim, realizamos, como defende Cosson (2011) um encontro dos estudantes com as raízes históricas da cidade e as materializamos nas produções.

\subsubsection{Resultados e discussões}

O ponto principal das nossas atividades foi a produção do livro, pois, concordando com Geraldi $(2006,65)$, "[...] qual a graça de escrever um texto que não será lido por ninguém ou que será lido apenas por uma pessoa (que por sinal corrigirá o texto e dará nota para ele)?”. Acreditamos que este produto final tenha ficado rico, pois em cada história ficaram marcas dos alunos: expressões, modos de escrever ou revelações de suas experiências individuais.

No inicio das atividades, quando informamos aos alunos que produziríamos um livro, eles acharam que estávamos de brincadeira, pois acreditavam que só pessoas de alto poder aquisitivo poderiam ser escritores, mas ao decorrer das práticas a motivação em escrever um livro era tanta que o desempenho nas atividades de leitura e escrita aumentaram significativamente. Além disso, aproveitamos a época da feira do livro na cidade e realizarmos uma apresentação do livro juntamente com uma sessão de autógrafos dada pelos alunos.

Ao decorrer das nossas atividades vivenciamos diversas situações prazerosas e outras nem tanto. Os alunos que fizeram parte desse projeto são, em sua maioria, carentes e buscam na escola um ambiente que disponha de afetividade, atividades interessantes, pois são crianças e jovens que provém de uma estrutura familiar conturbada. De acordo com o Projeto Político 
Pedagógico (s/d) da escola sua é filosofia “operar a transformação, possibilitando o crescimento humano, formando um homem aberto ao mundo, receptivo ao diálogo, flexível a mudanças, um cidadão crítico, com capacidades e responsabilidades, proporcionando uma visão ética do mundo". Além disso, tem por objetivo geral “oportunizar o pleno desenvolvimento dos educandos, formando cidadãos críticos e autônomos, respeitando a liberdade e o pluralismo de ideias, encorajando-os a transformar a realidade onde estão inseridos". Durante o nosso processo de construção de práticas de letramento houve alguns percalços, pois os alunos tiveram que participar de atividades de apresentações, ensaios da banda e etc, ocasionando uma quebra motivacional no processo de ensino/aprendizagem. Segundo Néreci,

[...] a motivação é fator decisivo no processo da aprendizagem. Não poderá haver, por parte do professor, direção da aprendizagem, se o aluno não estiver motivado, se não estiver disposto a despender esforços. Não há, de modo geral, aprendizagem sem esforço (NÉRECI, 1993, p. 75).

Dessa forma, acreditamos que, se nossas atividades tivessem sido aplicadas de forma sequencial e sem rupturas, os alunos teriam um engajamento maior no que tange a sua produtividade leitora e escritora.

Traçando um panorama geral das atividades, percebemos que o nível de leitura e escrita das crianças aumentou significativamente e, a partir das respostas dadas a um questionário de encerramento do projeto, vimos que o gosto pela leitura e escrita foi despertado, pois alguns relataram que gostariam de trabalhar com outros temas como desenhos animados, futebol e etc.

Em relação a nossa prática, podemos apontar um grande crescimento pessoal e profissional, pois a cada aula vivenciamos uma situação diferente. As experiências adquiridas nesse projeto nos proporcionaram um novo olhar frente à escola e aos alunos, acreditamos que é sempre bom vivenciar novas experiências, como a de ministrar aulas pelas vias de um projeto, já que é uma dinâmica totalmente diferente das que estamos acostumados a presenciar nas salas de aula regulares.

De modo geral, nos sentimos satisfeitos por proporcionar a esses alunos novas práticas e experiências que eles imaginavam estar fora do seu alcance, além disso, através do trabalho com as raízes de Jaguarão ressuscitamos uma cultura que não faz parte do cotidiano das crianças e jovens do séc. XXI, revelando como foi a criação do município por meio de lendas populares. 


\section{Considerações}

O propósito deste texto foi o de revelar possibilidades de trabalho a partir de uma concepção de letramento, em especial, de letramento literário. Os registros dos alunosestagiários, de suas práticas envolvendo a leitura e a escrita de textos literários mostraram a diversidade e riqueza de ações que podem perpassar a sala de aula de língua e literatura, transformando esse espaço em espaço de prazer, de aprendizagens significativas que mobilizam a criatividade, a criticidade e o desenvolvimento do prazer pela leitura e escrita.

Também, pudemos perceber o quão positivamente essa dinâmica, no estágio supervisionado, representou para os discentes de Letras. A ousadia em pensar práticas que, de algum modo, rompem com aquelas costumeiramente realizadas nas aulas de língua e literatura, indicou o potencial que os professores têm, se desejarem, em transformar a escola em um espaço de novas aprendizagens. Além disso, os alunos-estagiários foram construindo, juntamente com os alunos das escolas, um fazer que proporcionou a reflexão sobre escola, ensino, e sobre o ser professor, pois, como foi dito, a profissão professor não é fácil, nem simples, mas é vivida, sentida e deve ser movida pelo novo, pela ousadia de querer experienciar a novidade.

Temos a certeza de que o que propomos, pensando o letramento literário, tem muito a avançar. Essa foi uma das experiências vividas por mim - coordenadora do projeto e supervisora do estágio, pelos alunos-estagiários e pelos alunos das escolas. Seguiremos com outras propostas de ações, via o projeto Experiências de leitura/escrita: a formação de leitores/escritores com vistas ao desenvolvimento do letramento literário, e almejamos conquistar outros professores a engajarem-se nesse trabalho, tanto na universidade como nas escolas de educação básica.

\section{Referências}

BAHKTIN, M. Os gêneros do discurso. In: . Estética da criação verbal. 2. ed. São Paulo: Livraria Marfins Fontes Editora Ltda, 1997. Tradução de Maria Ermantina Galvão G. Pereira.

CARVALHO, M. F. N. de; PEREIRA, V. C.; FERREIRA, S. P. A. A (des)motivação da aprendizagem de alunos de escola pública de ensino fundamental I: quais os fatores envolvidos? Disponível em:

<https://www.ufpe.br/ce/images/Graduacao_pedagogia/pdf/2007.2/a\%20desmotivao\%20da\% 20aprendizagem\%20de\%20alunos\%20de\%20escola.pdf $>$. Acesso em: 05 jan. 2015. COSSON, Rildo. Letramento literário: teoria e prática. 2 ed. São Paulo: Contexto, 2011. 
SOARES, Magda. Letramento: um tema em três gêneros. 3. ed. Belo Horizonte: Autêntica Editora, 2012. . Alfabetização e letramento. 6. ed. São Paulo: Contexto, 2011.

KLEIMAN, A. B. Letramento e suas implicações para o ensino de língua materna. Signo. Santa Cruz do Sul, 2007. V. 32, n. 53, pp. 1-25.

GERALDI, João Wanderlei. Pratica de leitura na escola. In: GERALDI, João Wanderlei (org). O texto na sala de aula. São Paulo: Ática, 2006.

LEITE, Lígia Chiappinni de Moraes. Gramática e literatura: desencontros e esperanças. In:

GERALDI, João Wanderley. O texto na sala de aula, 3. ed. Rio de Janeiro: Ática, 2002. NÉRICI, Imídeo Giuseppe. Didática: uma introdução. 2. ed. São Paulo: Atlas, 1988. SANTOS, José Luiz. O que é Cultura. 14 ed. - São Paulo: Brasiliense, 1994. 